\title{
Hepatoprotective effect of red ginger rhizome extract in deep frying oil-fed male wistar rats
}

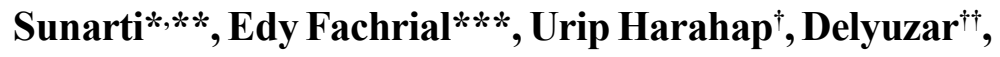 \\ Tri Widyawati ${ }^{\dagger \dagger}$, and Lokot Donna Lubis
}

\begin{tabular}{|c|}
\hline 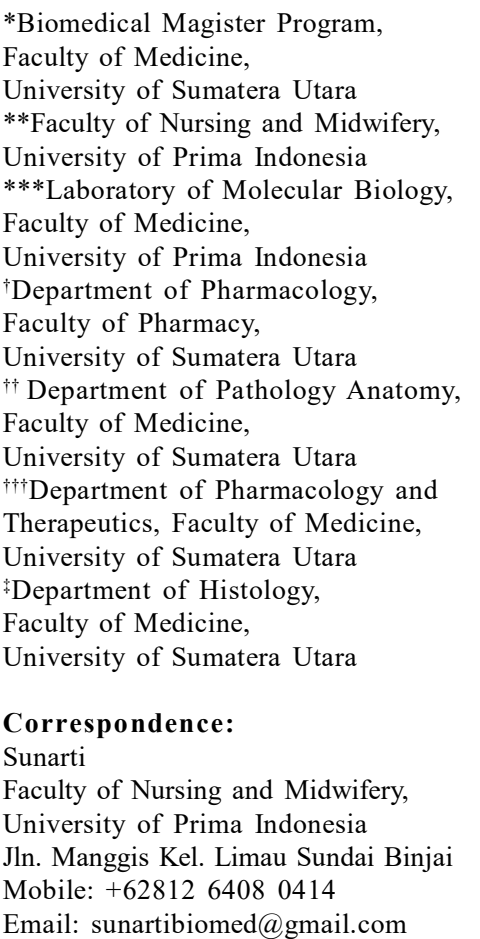 \\
\hline
\end{tabular}

Date of first submission, June 8, 2017 Date of final revised submission, November 6, 2017

Date of acceptance, November 8, 2017

This open access article is distributed under a Creative Commons AttributionNon Commercial-Share Alike 4.0 International License

Cite this article as: Sunarti, Fachrial E, Harahap U, et al. Hepatoprotective effect of red ginger rhizome extract in deep frying oil-fed male wistar rats. Univ Med 2017;36: 228-35. doi: 10.18051/ UnivMed.2017.v36.228-235

\section{BACKGROUND}

Non-alcoholic steatohepatitis (NASH) is a chronic liver disease associated with increased free fatty acids, trans fatty acids and free radical compounds due to the consumption of deep frying oil (DFO). Ginger has hypolipidemic and antioxidant properties, and acts as an insulin sensitizer. The present study was conducted to evaluate the hepatoprotective effect of an ethanol extract of Zingiber officinale Roxb var rubrum (EEZO) in DFO-fed male Wistar rats.

\section{METHODS}

A study of experimental design was conducted involving 24 non-alcoholic steatohepatitis (NASH) male Wistar rats that were randomly divided into 4 groups. Group K1 (control) was given DFO-3 (3 times heated DFO) at a dose of $10 \mu \mathrm{l} / \mathrm{g} \mathrm{BW} /$ day. The treatment groups (P1, P2, P3) were given DFO-3 and red ginger rhizome extract at doses of 100, 200, and $400 \mathrm{mg} / \mathrm{kg}$ BW orally for 30 days. The histopathology examination assessed fatty degeneration, and degree of fibrosis. The data were analyzed with the Kruskal-Wallis and Mann-whitney test.

\section{RESULTS}

The Kruskal-Wallis test showed that fatty degeneration (steatosis, lobular inflammation, hepatocyte ballooning and NASH) were significantly different among the four groups $(\mathrm{p}<0.05)$. Mann-Whitney test proved that fatty degeneration was not significantly different between control and treatment groups ( $\mathrm{p}>0.05)$.

\section{CONCLUSION}

Deep frying oil increased fatty degeneration and NASH, and none of red ginger rhizome extract doses was able to inhibit fatty degeneration significantly. For the future research it is intended to prolong the induction time and the administration of red ginger rhizome extract.

Keywords: NASH, red ginger rhizome extract, fatty degeneration, fibrosis, rats 


\section{INTRODUCTION}

Non-alcoholic fatty liver disease (NAFLD) is a chronic condition that is histopathologically characterized by more than 5 to $10 \%$ of macrovesicular liver steatosis and is not due to alcohol consumption. Non-alcoholic fatty liver disease is categorized into non-alchoholic fatty liver (NAFL) and non-alchoholic steatohepatitis (NASH). The NASH is a chronic condition that is histopathologically characterized by hepatic steatosis and inflammation with hepatocyte injury (ballooning) with or without fibrosis. ${ }^{(1,2)}$ The prevalence of NAFLD worldwide is estimated to be between $6.3 \%$ and $33 \% .^{(2)}$ In the United States the incidence of NAFLD in 2012 in the United States was up to $27-34 \%$, in Europe it reached $20-30 \%$ and in Asian countries such as Sri Lanka, Malaysia, and Indonesia it reached $15-20 \%$, while $2-3 \%$ of the general population is estimated to have NASH. ${ }^{(3)}$

Non-alcoholic steatohepatitis is considered to be one of the causes of chronic liver disease. The hazards of fatty liver are hepatic cirrhosis and liver cancer, due to liver inflammation from steatosis. ${ }^{(4)}$ One of the causes are free fatty acids, free radical compounds and trans fatty acids, which can be produced by deep frying oil (DFO). ${ }^{(5-7)}$ Trans fatty acids are able to increase lipid peroxidation, and the lipid peroxides formed will damage the rough endoplasmic reticulum so that the synthesis of lipoprotein-forming proteins is impaired. Low lipoprotein levels cause some of the fat in the liver to not bind to lipoproteins to be transported to other parts of need. The accumulation of fat in the liver causes fatty degeneration of the liver cells. Degeneration is a change in cell morphology due to injury. Cell injury causes changes in intracellular metabolism that subsequently alter the cell structure. ${ }^{(8)}$

Lipid peroxidation is characterized by increased malondialdehyde (MDA) and decreased antioxidant enzymes such as catalase (CAT), superoxide dismutase (SOD) and glutathione peroxidase (GPx), that cause oxidative stress. ${ }^{(9)}$
The resulting oxidative stress or reactive oxygen species (ROS) destroys mitochondrial deoxyribonucleic acid (DNA) and increases the expression of proinflammatory cytokines [tumor necrosis factor alpha (TNF- $\alpha$ ), transforming growth factor beta (TGF- $\beta$ ), interleukin-8 (IL-8)], so increasing the formation of Mallory bodies and collagen synthesis in the stellate cells. The ROS will also cause apoptosis directly through the nuclear factor- $\kappa \mathrm{B}(\mathrm{NF}-\kappa \mathrm{B})$ activation, thereby causing injury to the liver, inflammation and development of fibrosis. ${ }^{(10,11)}$

Zingiber officinale Roxb var rubrum (ZO) reportedly contains flavonoids, polyphenols and tannins, that are known to have antioxidant activity. ${ }^{(12)}$ And is able to inhibit lipid peroxidation, to increase antioxidant enzymes, to regulate the low density lipoprotein (LDL) receptors and 3hydroxy-3-methylglutaryl coenzyme-A (HMGCoA) that affect the absorption of cholesterol in the liver. ${ }^{(13)}$ The $\mathrm{ZO}$ component zingerone is particularly effective as a free radical scavenger of superoxide, hydroxyl, nitric oxide (NO), peroxyl and peroxynitrite radicals in vitro. Gingerol is also an effective peroxyl radical scavenger and inhibits NO formation. Therefore, 6-gingerol (the most abundant gingerol) and zingerone effectively inhibit lipid peroxidation due to the generation of ROS. ${ }^{(14)}$

Phytochemical studies showed that ZO is rich in a large number of substances, including gingerols and shogaols, the dehydrated form of gingerols. These compounds display diverse biological activities such as antioxidant, anti inflammatory, and anticarcinogenic properties. ${ }^{(15)}$ A study on 30 male Wistar rats given DFO at a dose of $0.42 \mathrm{ml}$ per day for 14 days found increased steatosis, leading to the development of fatty liver. ${ }^{(16)}$ Another study, in which 48 rats were fed a high cholesterol diet and received an aqueous infusion of ginger orally at doses of 100 , 200 and $400 \mathrm{mg} / \mathrm{kg} \mathrm{BW}$ in comparison with atorvastatin, found that the doses of 200 and 400 $\mathrm{mg} / \mathrm{kg}$ BW lowered cholesterol more effectively than did atorvastatin. ${ }^{(17)}$ Yet another study showed that oils from Z. officinale $(200 \mathrm{mg} / \mathrm{kg})$ exhibited 
hepatoprotective activity in acute ethanol-induced fatty liver in male Wistar rats. ${ }^{(18)}$

A study on male Wistar rats that were fed used frying oil showed that there were a large number of dark-red patches, necrosis, and bleeding in the liver, while the renal cells were also obviously damaged. ${ }^{(19)}$ However, no information could be obtained from previous studies on the effects of an ethanol extract of red ginger rhizome on NASH. The objective of the present study was to evaluate the hepatoprotective effect of an ethanol extract of red ginger rhizome on the histopathology of NASH in DFO-fed male Wistar rats.

\section{METHODS}

\section{Research design}

This study was of a randomized post-test only control group design, in which the control and treatment groups were each treated differently. The study was conducted in the animal breeding house in the Pharmacy Laboratory, while the histopathology examination was conducted in the Laboratory of Histology, Medical Faculty, Universitas Sumatera Utara from September 2016 to January 2017.

\section{Plant material}

Red ginger rhizomes were collected from Raya Simalungun and have been identified in the Herbarium Medanese Laboratory of Universitas Sumatera Utara under number 871/MEDA/2016.

\section{Preparation of red ginger rhizome extract}

Red ginger rhizomes were washed and then dried in a drying oven at a temperature of $60^{\circ} \mathrm{C}$. After drying, the rhizomes were then crushed in an electric blender. The simplicia homogenate powder was macerated in $96 \%$ ethanol. After filtration, the extract was evaporated using a rotary evaporator at a temperature range of 40 $60^{\circ} \mathrm{C}$ until it had thickened. The solutions made from the extract were prepared freshly each time and were administered orally once daily for 30 days to the treatment groups.
Standardization of simplicia and extract was based on the Indonesian Pharmacopeia 2014, ${ }^{(20)}$ to calculate the water content, water soluble extract, ethanol soluble extract, total ash content and acid soluble ash content. ${ }^{(20)}$ Identification of the phytochemicals in red ginger rhizome ethanol extract was based on Yang et al. ${ }^{(21)}$ to identify flavonoids, alkaloids, tannins, saponins, steroids and terpenoids as well as glycosides.

\section{Preparation of deep frying oil}

Deep frying oil was made by frying $5 \mathrm{~kg}$ catfish 3 times in 2.5 liter cooking palm oil at $200^{\circ} \mathrm{C}$ (measured with a cooking thermometer) for 15 minutes. After each frying the oil was left to cool for \pm 5 hours at room temperature. The 3-times heated DFO preparation will subsequently be referred to as DFO-3.

\section{Experimental animals}

The experimental animals were 24 healthy male Wistar rats aged 2-3 months and weighing between 200 and $250 \mathrm{~g}$. The rats were divided by simple randomization into 4 groups of 6 animals per group, by using the formula of Federer: (t-1) (n-1) $\geq 15$. ${ }^{(22)}$ The animals were acclimatized at room temperature $\left(25-30^{\circ} \mathrm{C}\right)$ for one week under a 12 hour light-and-dark cycle. Food was given orally ad libitum in the form of the CP 551 standard animal feed concentrate from PT. Charoen Pokphand, Tanjung Morawa, Medan.

\section{Experimental procedure}

The interventions were based on the treatment group. Group K1 (control) was given standard diet and DFO-3 + distilled water $+1 \mathrm{ml}$ of $1 \%$ sodium carboxymethyl cellulose (Na$\mathrm{CMC}$ ), and treatment groups P1, P2, P3 were given orally standard diet and DFO-3 + distilled water $+1 \mathrm{ml}$ of $1 \% \mathrm{Na}-\mathrm{CMC}$ and red ginger rhizome extract at stratified dosages of 100, 200 and $400 \mathrm{mg} / \mathrm{kg} \mathrm{BW}$, administered daily for 30 days. At the end of the treatment on the $37^{\text {th }}$ day (of acclimatization and treatment), the rats were anesthetized by using ketamine xylazine at doses of $75-100 \mathrm{mg} / \mathrm{kg}+5-10 \mathrm{mg} / \mathrm{kg}$ intraperitoneally 
for 10-30 minutes. Then surgical laparatomy was performed to remove the liver, which was prepared for histological analysis.

\section{Histological analysis}

The slide preparations for histological analysis were stained with hematoxylin and eosin (H\&E) for the assessment of lipid degeneration and with Masson's trichrome stain for the assessment of fibrosis, then examined microscopically. The preparations successively underwent fixation, washing, dehydration, clearing, embedding, sectioning, affixing, staining, mounting and labeling. ${ }^{(23)}$

The stained slides were analyzed under the light microscope at 400x magnification. Blind labeling was performed randomly on 24 slides. Fat droplet-containing liver cells were counted in four areas around the central veins of randomly selected liver lobules and then the mean number of fat droplets was calculated from the total number of fat droplets in all areas. The degree of fibrosis was determined according to Brunt. ${ }^{(24)}$

\section{Statistical analysis}

The data were not normally distributed. The Kruskal-Wallis test was followed by the MannWhitney test to analyze the data. Significance was set at $\mathrm{p}<0.05$.

\section{Ethical clearance}

The study was conducted according to the ethical clearance from the Animal Research Ethics Committee of the Faculty of Mathematics and Natural Sciences, Universitas Sumatera Utara (FMIPA USU), Medan, under number 589/ KEPH-FMIPA/2016.

\section{RESULTS}

The standardization of the $\mathrm{ZO}$ ethanol extract (EEZO) yielded the following results: water content of simplicia $(7.50 \%)$, extract (4.90\%), water soluble content (21.70\%), ethanol soluble concentration (10.43\%), total ash content $(3.42 \%)$ and acid soluble ash $(1.32 \%)$. The phytochemical screening of simplicia and EEZO traced the presence of alkaloids, saponins, tannins, flavonoids, steroids, triterpenes and glycosides.

Fatty degeneration was found in 24 male Wistar rat liver tissue samples with $\mathrm{H} \& \mathrm{E}$ staining, as shown in Figures 1A and 1B. The histologic sections in some groups showed steatosis, lobular inflammation and hepatocyte ballooning after 30 days of DFO administration. Figure 1C shows decreased lobular inflammation with neutrophils in normal sinusoids after administration of red ginger extract at the dose of $200 \mathrm{mg} / \mathrm{kg} \mathrm{BW}$.
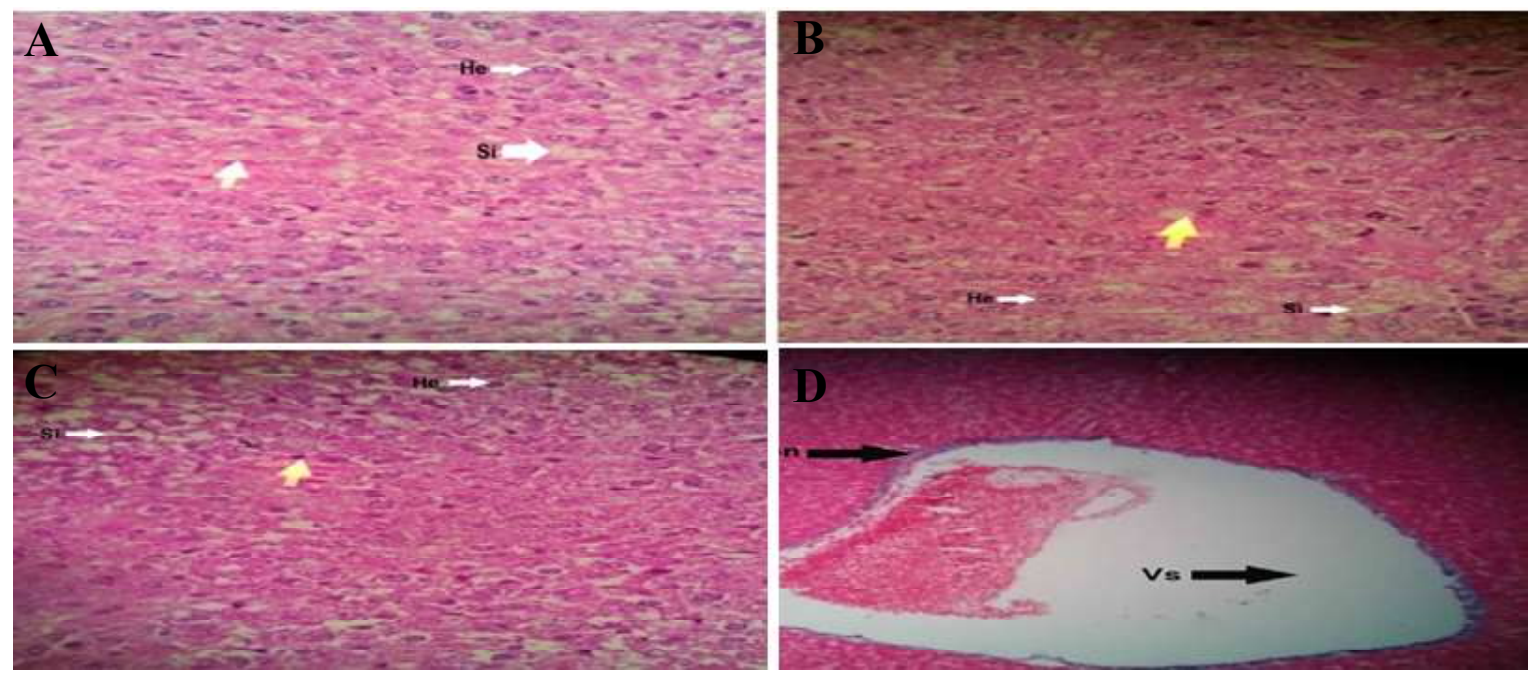

Figure 1. Histopathology of lipid degeneration; $\mathrm{Si}=$ sinusoid, $\mathrm{He}=$ hepatocyte, Vs=central vein, A. Steatosis B. ballooning of hepatocyte C. lobular inflammation (H\&E stain), D. Arrows show collagen fibers clearly visible surrounding the central vein (F0) (Masson's trichrome stain) 
Determination of the degree of fibrosis was performed on 24 male Wistar rat liver tissue samples with Masson's trichrome staining, as shown in Figure 1D. The image shows that the Masson's trichrome staining was successful, with a perfect color of collagen fibers clearly visible between the central veins. Therefore it can be concluded that in this study the collagen fibers were normal ( $\mathrm{F} 0=$ no fibrosis).

The result of Kruskal-Wallis test showed that the number of hepatocytes with steatosis $(p=0.001)$, lobular inflammation $(p=0.001)$, hepatocyte ballooning $(\mathrm{p}=0.000)$ and NASH $(\mathrm{p}=0.001)$ were significantly different between the four groups (Table 1).

The result of Mann-Whitney test showed the comparison between KI (control) and treatment groups (P1, P2, P3) with regard to the effect of DFO-3 on the number of hepatocytes with steatosis, lobular inflammation, hepatocyte ballooning and NASH grade, there was no significant difference between the four groups ( $p>0.05$ ). There was only a significant difference in the amount of steatosis between the control group and the treatment group P1 at the dose of $100 \mathrm{mg} / \mathrm{kgBW}$. It can be seen from the result that the amount of steatosis was greater in the treatment group than in the control group (data not shown).

\section{DISCUSSION}

This study showed that the administration of deep frying oil can increase the amount of steatosis, lobular inflammation, hepatocyte ballooning and NASH grade. Although the administration of red ginger rhizome ethanol extract did not significantly decrease the histopathologic abnormalities, at a dose of 200 $\mathrm{mg} / \mathrm{kg} \mathrm{BW}$ the result was better than that in the other groups. In another study on the administration of aqueous extract of ginger to Sprague Dawley rats at a dose of $400 \mathrm{mg} / \mathrm{kg}$ $\mathrm{BW}$, it was found that EEZO can be used as an anti-inflammatory agent. ${ }^{(25)}$ In another histopathological study on acute and chronic models of inflammation in Wistar rats, it was found that administration of an aqueous ginger extract decreased granulation tissue, inflammatory cells and fibroblasts as compared to controls. ${ }^{(26)}$

This is supported by another study, which found that red ginger rhizome can decrease fatty degeneration which is influenced by anti oxidant compounds such as flavonoids and tannins as free radical scavengers that can decrease the formation of proinflammatory cytokines and increase the formation of lipoprotein as a fat carrier in the liver. ${ }^{(27)}$

In previous studies the doses of 100, 200, and $400 \mathrm{mg} / \mathrm{kg}$ BW could decrease fatty degeneration of the liver using an assessment of the enzymatic system, but in the present study only the dose of $200 \mathrm{mg} / \mathrm{kg} \mathrm{BW}$ was able to reduce fatty degeneration of the liver. The present study was directly assessed on the gold standard of liver histology, especially hepatocyte degeneration (amount of steatosis, lobular inflammation, hepatocyte ballooning), NASH and fibrosis.

Decreased fatty degeneration is due to the fact that the red ginger rhizome has an antioxidant content of flavonoids. Flavonoids are compounds

Table 1. Effect of ethanol extract of red ginger rhizome on liver histopathology in DFO-fed male Wistar rats

\begin{tabular}{lccccc}
\hline Histopathology & K1 $(\mathbf{n}=\mathbf{6})$ & P1 $(\mathbf{n}=\mathbf{6})$ & P2 $(\mathbf{n}=\mathbf{6})$ & P3 $(\mathbf{n}=\mathbf{6})$ & p value \\
\hline Steatosis & 0.00 & $1.00^{*}$ & 0.00 & 1.00 & 0.001 \\
Lobular inflammation & 1.00 & 1.00 & 0.00 & 1.00 & 0.001 \\
Hepatocyte ballooning & 0.00 & 0.00 & 0.00 & 0.00 & 0.000 \\
NASH & 0.50 & 1.00 & 0.00 & 1.00 & 0.001 \\
\hline
\end{tabular}

Data presented as median; *Significant at $\mathrm{p}<0.05$ by Mann-Whitney test; NASH : non-alcoholic steatohepatitis; K1: norma diet +DFO-3 (10 $\mu \mathrm{l} / \mathrm{g} /$ day $)$ as control; P1: normal diet + DFO-3 + EEZO (100 mg/kg once daily); P2: normal diet + DFO-3 $+\operatorname{EEZO}(200 \mathrm{mg} / \mathrm{kg}$ once daily); P3: normal diet + DFO-3 + EEZO (400 mg/kg once daily) 
belonging to the phenolic group. The main phenolics in red ginger are gingerol and shogaol, that are more effective than quercetin. ${ }^{(28)}$

A phenolic has one aromatic ring $\mathrm{A}$, one aromatic ring $\mathrm{B}$, and an oxygen-containing middle ring and contains one or more hydroxyl groups. ${ }^{(29)}$ The hydroxyl group in phenolics is a group that has antioxidant activity and plays an important role as free radical scavenger, due to its ability to donate hydrogen atoms, thereby stabilizing free radical compounds. ${ }^{(30,31)}$

High temperature frying at $200^{\circ} \mathrm{C}$ converts trans fatty acids through thermal polymerization and oxidation reactions after a second repeat frying for 30 minutes. ${ }^{(32)}$ Trans fatty acids (TFA) inhibit the activity of enzymes for lipid metabolism, such as fatty acid desaturase elongase and lecithin cholesterol acyl transferase (LCAT); the latter plays a role in the metabolism of high-density lipoprotein cholesterol (HDL), i.e. the transport of cholesterol from the tissues to the liver, to be reconverted into very low density lipoprotein. ${ }^{(33)}$ In our study the formation of fatty acids in the liver was due to excessive accumulation of fat after administration of DFO3 in volumes of $10 \mu \mathrm{l} / \mathrm{g}$ BW for 30 days. Heating oil at the high temperatures for frying will decrease the quality of the oil and can induce NAFLD. ${ }^{(34)}$

Deep frying oil has a high trans fatty acid (TFA) and mono-unsaturated fatty acid (MUFA) content. ${ }^{(35)}$ It decreases the efficiency of antioxidant enzyme systems by increasing pro-inflammatory signals, thus increasing oxidative stress. It can cause failure of the liver in synthesizing apolipoprotein B-100 (apo B-100) to transport fat from the liver and prevent triglyceride and LDL accumulation. ${ }^{(36)}$

When viewed from the effect of the EEZO dose, it was found that a dose of $200 \mathrm{mg} / \mathrm{kg} \mathrm{BW} /$ day was effective in reducing steatosis, lobular inflammation and degree of $\mathrm{NASH}$ in comparison with the control group (K1). The effectiveness of EEZO at the dose of $200 \mathrm{mg} /$ $\mathrm{kg} \mathrm{BW/day,} \mathrm{proves} \mathrm{the} \mathrm{concept} \mathrm{of} \mathrm{drug} \mathrm{or}$ vitamin consumption, because each drug or vitamin has different dosage rules so as not to harm or cause new diseases. Previous results also stated that EEZO at the dose of $200 \mathrm{mg} / \mathrm{kg}$ $\mathrm{BW}$ significantly decreased pro-cytokines such as (IL-1 $\beta$, IL-2, IL-6 and TNF- $\alpha){ }^{(37)}$ The results of our study in using multilevel dosages in the administration of EEZO with DFO-3 showed no significant difference in the decrease in steatosis, lobular inflammation, hepatocyte ballooning, NASH and fibrosis (F0). This may be induced and it requires a longer duration of therapy to affect a more optimal improvement of the liver tissue. Therefore, high doses of EEZO increase the intake of gingerol in the body. The gingerol compound is spicy, so high doses cause irritation which has the potential to increase liver injury, thus exacerbating hepatocyte steatosis. This study did not measure the duration of EEZO administration, so further studies need to consider the duration of treatment to evaluate the hepatoprotective effect of EEZO.

\section{CONCLUSIONS}

Ethanol extract of $Z$. officinale effectively reduces the amount of steatosis, lobular inflammation and NASH. However, there was no significant difference in the treatment at the doses of 100, 200 and $400 \mathrm{mg} / \mathrm{kg} \mathrm{BW}$. This study concludes to favor ginger but further research is required before its efficacy can be claimed.

\section{CONFLICT OF INTEREST}

The authors declare that there was no conflict of interest between the authors and the study subjects.

\section{ACKNOWLEDGMENTS}

The authors are especially grateful to the Directorate General of Higher Education (Ditjen Dikti) who has provided fund support in this study. Thanks are also due to the Biomedical Master Program, Medical Faculty, Sumatera Utara University. 


\section{CONTRIBUTORS}

SN contributed to the design of the study, drafting of the manuscript and was responsible for the final content. SN, EF, UH, and DY contributed to data collection, analysis and interpretation. TW and LDL contributed to revising the manuscript critically for important intellectual content. All authors read and approved the final version.

\section{REFERENCES}

1. Kelishadi R, Farajian S, Mirlohi M. Probiotics as a novel treatment for non-alcoholic fatty liver disease: a systematic review on the current evidences. Hepat Mon 2013;13:1-8.

2. Chalasani N, Younossi Z, Lavine JE, et al. The diagnosis and management of non-alcoholic fatty liver disease: practice guideline by the American Association for the Study of Liver Diseases, American College of Gastroenterology, and the American Gastroenterological Association. Hepatology 2012;55:2005-23.

3. Chowdhury A, Younossi ZM. Global epidemiology and risk factors for nonalcoholic fatty liver disease. In: Chalasani N, Szabo,editors. Alcoholic and non-alcoholic fatty liver disease. Geneva: Springer international Publishing Switzerland;2016.p. 21-404.

4. Farrell GC, Wong VW-S, Chitturi S. NAFLD in Asia-as common and important as in the West. Nat Rev Gastroenterol Hepatol 2013;10:307-18.

5. Oeij AA, Atmadja WL, Achmad S, et al. Gambaran anatomi mikroskopik dan kadar malondialdehida pada hati mencit setelah pemberian minyak kelapa sawit bekas menggoreng. JKM 2007;7:14-25.

6. Marinova EM, Seizova KA, Totseva IR, et al. Oxidative changes in some vegetable oils during heating at frying temperature. Bulg Chem Commun 2012;44:57-63.

7. Farag RS, Abdul-Latef MS, Basuny AMM, et al. Effect of non-fried and fried oils of varied fatty acid composition on rat organs. Agric Biol J N Am 2010;1:501-9.

8. Dewi R, Sutejo IR. Administration of used cooking oil to mice causes liver cell damage and decreases serum albumin. Moluca Medica 2011;4:61-9.

9. Dhibi M, Brahmi F, Mnari A, et al. The intake of high fat diet with different trans fatty acid levels differentially induces oxidative stress and non alcoholic fatty liver disease (NAFLD) in rats. Nutr Metab 2011;8:65. doi: 10.1186/1743-7075-8-65.
10. Martin-Dominguez V, Gonzalez-Casas R, Mendoza-Jimenez-Ridruejo J, et al. Pathogenesis, diagnosis and treatment of non-alcoholic fatty liver disease. Rev Española Enfermedades Dig 2013;105:409-20.

11. Jurnalis YD, Sayoeti Y, Elfitrimelly. Role of antioxidants in non-alcoholic fatty liver disease (NAFLD). J Kesehatan Andalas 2014;3:15-20.

12. Shirin APR, Jamuna P. Chemical composition and antioxidant properties of ginger root (Zingiber officinale). J Med Plants Res 2010;4:2674-9.

13. Nammi S, Kim MS, Gavande NS, et al. Regulation of low-density lipoprotein receptor and 3hydroxy-3-methylglutaryl coenzyme A reductase expression by Zingiber officinale in the liver of high-fat diet-fed rats. Basic Clin Pharmacol Toxicol 2010;106:389-95.

14. Haniadka R, Saxena A, Shivashankara AR, et al. Ginger protects the liver against the toxic effects of xenobiotic compounds: preclinical observations. J Nutr Food Sci 2013;3:226. doi: 10.4172/2155-9600.1000226.

15. El-Abhar HS, Hammad LN, Gawad HS. Modulating effect of ginger extract on rats with ulcerative colitis. J Ethnopharmacol 2008;118:36772.

16. Setiawan A. Alpha lipoic acid oral inhibits improvement in number of steatosis and ALT levels in waste oil induced of male Wistar rat [tesis]. Denpasar: Universitas Udayana;2014.

17. Elrokh ESM, Yassin NAZ, El-Shenawy SMA, et al. Antihypercholesterolaemic effect of ginger rhizome (Zingiber officinale) in rats. Inflammopharmacology 2010;18:309-15.

18. Nwozo SO, Osunmadewa DA, Oyinloye BE. Antifatty liver effects of oils from Zingiber officinale and Curcuma longa on ethanol-induced fatty liver in rats. J Integr Med 2014;12:59-65.

19. Totani N, Ojiri Y. Mild ingestion of used frying oil damages hepatic and renal cells in Wistar rats. $\mathrm{J}$ Oleo Sci 2007;56:261-7

20. Departemen Kesehatan RI, Farmakope Indonesia. edition V. Jakarta: Departemen Kesehatan Republik Indonesia; 2014.

21. Yang Z, Yang W, Peng Q, et al. Volatile phytochemical composition of rhizome of ginger after extraction by headspace solid-phase microextraction, petrol ether extraction and steam distillation extraction. Bangladesh J Pharmacol 2009;4:136-43.

22. Wahyuningrum MR, Probosari E. The effect of papaya fruit (Carica papaya L.) on triglyceride levels in hypercholesterolemic Sprague Dawley rats. J Nutr Coll 2012;1:192-8 .

23. Novriansyah R. Differences in collagen density around wounds incision in conventional wrinkle 
and occlusive hydrocolloid closures for 2 and 14 days [thesis]. Semarang: Universitas Diponegoro; 2008.

24. Brunt EM. Nonalcoholic fatty liver disease: pros and cons of histologic systems of evaluation. Int J Mol Sci 2016;17: 97. doi: 10.3390/ijms17010097.

25. Hassan NA, Karunakaran R, Uma SA, et al. Antiinflammatory effect of Zingiber officinale on Sprague Dawley rats. Asian J Pharm Clin Res 2017;10:3-5.

26. Malipatil NB, Manjunath S, Shruthi DP. Evaluation of effect of aqueous extract of Zingiber officinale Roscoe (Ginger) on acute and chronic inflammation in adult albino rats. Asian $\mathrm{J}$ Pharm Clin Res 2015;8:113-6.

27. Kumar S, Saxena K, Singh UN, et al. Antiinflammatory action of ginger: A critical review in anemia of inflammation and its future aspects. Int J Herb Med 2013;116-20.

28. Stoilova I, Krastanov AI, Stoyanova A, et al. Antioxidant activity of a ginger extract (Zingiber officinale). Food Chem 2007;102:764-70.

29. Redha A. Flavonoids: structure, antioxidative properties and their roles in biological systems J Belian 2010;9:196-202.

30. Vamanu E. In vitro antimicrobial and antioxidant activities of ethanolic extract of lyophilized mycelium of Pleurotus ostreatus PQMZ91109. Molecules 2012;17:3653-71.

31. Adawiah, Sukandar D, Muawanah A. Antioxidant activity and content of bioactive components of namnam fruit juice. Valens J Chem 2015;1:127-33.

32. Sartika RAD. Effect of temperature and duration of frying (deep frying) on the formation of trans fatty acids. Makara Sains 2009;13:23-8.

33. Sartika RAD. Effects of saturated, unsaturated and trans fatty acids on health. Kes Mas 2008;2: 154-60.

34. Susianti. The effect of cooking oil refined with noni fruit (Morinda citrifolia) on the histopathology of rat liver and heart. MKA 2014; 37:54-60.

35. Bruhl L. Fatty acid alterations in oils and fats during heating and frying. Eur J Lipid Sci Technol 2014;116:707-15.

36. Labonte ME, Jenkins DJA, Lewis GF, et al. Adding MUFA to a dietary portfolio of cholesterollowering foods reduces apoAI fractional catabolic rate in subjects with dyslipidaemia. Br J Nutr 2013; 110:426-36.

37. Fouda A, Berika M. Evaluation of the effect of hydroalcoholic extract of Zingiber officinale rhizomes in rat collagen-induced arthritis. Basic Clin Pharmacol Toxicol 2009;104:262-71 . 